\title{
Genetic diversity of Coxsackievirus A21 associated with sporadic cases of acute respiratory infections in Malaysia
}

\author{
Nur Izzati Supian', Kim Tien Ng ${ }^{2,3,4}$, Jack Bee Chook ${ }^{5}$, Yutaka Takebe ${ }^{1,6}$, Kok Gan Chan ${ }^{7,8}$ and Kok Keng Tee ${ }^{1,5^{*}}$ (D)
}

\begin{abstract}
Background: Coxsackievirus A21 (CVA21), a member of Enterovirus C from the Picornaviridae family, has been associated with respiratory illnesses in humans.

Methods: A molecular epidemiological investigation of CVA21 was conducted among patients presenting with acute upper respiratory illnesses in the ambulatory settings between 2012 and 2014 in Kuala Lumpur, Malaysia.

Results: Epidemiological surveillance of acute respiratory infections $(n=3935)$ showed low-level detection of CVA21 $(0.08 \%, 1.4$ cases/year) in Kuala Lumpur, with no clear seasonal distribution. Phylogenetic analysis of the new complete genomes showed close relationship with CVA21 strains from China and the United States. Spatiotemporal mapping of the VP1 gene determined 2 major clusters circulating worldwide, with inter-country lineage migration and strain replacement occurring over time.
\end{abstract}

Conclusions: The study highlights the emerging role of CVA21 in causing sporadic acute respiratory outbreaks.

Keywords: Enterovirus, Coxsackievirus, Acute respiratory tract infections, Outbreak

\section{Background}

Enteroviruses (EV) are a diverse group of nonenveloped, positive-sense RNA virus which belongs to the family Picornaviridae. EV are subdivided into 15 species within the genus Enterovirus, which consists of Enterovirus $A$ to Enterovirus $L$ and Rhinovirus $A$ to Rhinovirus $C$ (RV-A to RV-C) [1, 2]. Coxsackievirus A21 (CVA21), which belongs to the Enterovirus $C$ species, was first identified in a poliomyelitis outbreak in the summer of 1947 [3]. Similar to other enteroviruses, CVA21 have been associated with various respiratory, gastrointestinal and neurological symptoms in humans. In recent years, the role of CVA21 in causing sporadic

\footnotetext{
* Correspondence: k2tee@um.edu.my

'Department of Medical Microbiology, Faculty of Medicine, University of Malaya, Kuala Lumpur, Malaysia

${ }^{5}$ Department of Medical Sciences, School of Healthcare and Medical Sciences, Sunway University, Bandar Sunway, Selangor Darul Ehsan, Malaysia Full list of author information is available at the end of the article
}

outbreaks of respiratory infections in humans has become increasingly important $[4,5]$. Most notably, in what appeared as the first reported large CVA21 outbreak in China, CVA21 was detected in about $57 \%$ of patients in a cluster of unexplained respiratory illnesses in 2016, with evidence of efficient human-to-human transmission [6]. Another recent outbreak reported that CVA21 was detected in 16\% of military recruits with respiratory diseases, including febrile illness and pneumonia in the United States in 2002 [7].

Despite the clinical implications of enterovirus infection, CVA21 remains a rare serotype $[8,9]$ where routine diagnosis is very often not readily available in the healthcare settings which results in the under-reporting of CVA21 cases. Similarly, epidemiological surveillance and genetic characterization of CVA21 remain limited especially in the developing countries where respiratory disease burden is high [10]. In this study, we determined

(c) The Author(s). 2021 Open Access This article is licensed under a Creative Commons Attribution 4.0 International License, which permits use, sharing, adaptation, distribution and reproduction in any medium or format, as long as you give appropriate credit to the original author(s) and the source, provide a link to the Creative Commons licence, and indicate if changes were made. The images or other third party material in this article are included in the article's Creative Commons licence, unless indicated otherwise in a credit line to the material. If material is not included in the article's Creative Commons licence and your intended use is not permitted by statutory regulation or exceeds the permitted use, you will need to obtain permission directly from the copyright holder. To view a copy of this licence, visit http://creativecommons.org/licenses/by/4.0/ The Creative Commons Public Domain Dedication waiver (http://creativecommons.org/publicdomain/zero/1.0/) applies to the data made available in this article, unless otherwise stated in a credit line to the data. 
the distribution and analysed the first complete genomes of CVA21 among patients presenting with acute respiratory symptoms in Kuala Lumpur, Malaysia located in the Southeast Asia region.

\section{Methods}

From March 2012 to May 2014, respiratory samples in the form of nasopharyngeal swab were collected from 3935 consenting outpatients presenting with acute respiratory tract infections at the Primary Care Clinics, University of Malaya Medical Centre in Kuala Lumpur, Malaysia. Specimens were screened for viral pathogens using the xTAG Respiratory Viral Panel FAST Assay (Luminex Molecular, Toronto, Canada) followed by specific enterovirus detection by PCR amplification and phylogenetic analysis [11]. The complete genomes of CVA21 strains were amplified and sequenced using 18 pairs of newly designed primers (Supplementary Table 1). The overlapping fragments were assembled to obtain the complete genome. The genomes were aligned with other previously reported CVA21 sequences $(n=21)$ retrieved from the GenBank (accessed on 15 December 2020). Phylogenetic trees were constructed by the neighbour-joining method based on the Kimura twoparameter model implemented in MEGA X [12]. The reliability of the branching orders was analysed by bootstrap analysis of 1000 replicates. Similarity plot analysis was performed to investigate the possible occurrence of recombination in the genomes. Neighbour-joining tree was also reconstructed based on the VP1 region $(n=54$; accessed on 15 December 2020), using the approach employed in the complete genome analysis. This study was approved by the University Malaya Medical Centre Medical Ethics Committee (MEC890.1).

\section{Results and discussion}

During the epidemiological surveillance, a total of 3/ 3935 (0.08\%) cases of CVA21 infection were detected among outpatients presenting with acute respiratory symptoms (Table 1). Two CVA21 cases were identified in May 2012; patient 12MYKLU412 was a 52-year-old female presented with mild respiratory symptoms, and patient 12MYKLU434 was a 16-year-old male with severe headache and sore throat. Another patient
14MYKLU3370 was a 26-year-old female presented on January 2014 with severe headache and nasal congestion. No distinct distribution pattern or seasonality was observed, indicative of the sporadic nature of CVA21 infections $[4,8,9]$. However, the increased detection of CVA21 in May 2012 may be suggestive of a modest outbreak that occurred undetected in the population, although more data is needed to confirm it. Overall, the rate of detection was estimated at 1.4 cases/year in Kuala Lumpur, Malaysia, as compared to 0.65, 0.77, 1.2 and 9.2 cases/year reported in Japan, Singapore, United States and China, respectively $[4,5,8,13]$.

The three complete CVA21 genomes were 7339 nucleotides (nt) in length, which consist of a 690-nt $5^{\prime}$ untranslated region (UTR), followed by a 6621-nt polyprotein region encoding an open reading frame of 2207 codons, and the 3' UTR region. The genome organization of these genomes was similar to that of previously reported CVA21 prototype strains [14]. The average percentage of bases for all three genomes were 30.4\% A, 22.3\% G, 22.1\% C and 25.2\% U. Phylogenetic analysis based on all available CVA21 complete genomes in GenBank showed that strains from 12MYKLU412 and 12MYKLU434 were grouped within a cluster $(1.07 \%$ mean genetic distance) with the JN12377/SD/CHN/2012 strain (accession no. KT161266) isolated from environmental sewage in Shandong Province, China in 2012 (Fig. 1). Strain isolated from 14MYKLU3370 meanwhile was closely related to a recent outbreak strain 16SF042/ CHN/2016 (accession no. KY284011) isolated in Guangdong Province, China and the USA/TN/2015-OB2038 strain (accession no. KY271947) isolated from stool in Tennessee, United States. No significant evidence of recombination was detected in these genomes in the similarity plot analysis (data not shown).

In order to attain a greater spatio-temporal resolution for the global CVA21 strains, phylogenetic analysis based on all available $V P 1$ coding region $(n=54)$ showed that the contemporary CVA21 strains can be divided into two clusters; cluster I and II (Fig. 2) [9]. Cluster I comprised of CVA21 strains isolated from East Asia (China, Japan and Malaysia), North America (United States), Australia and Europe (Russia). Of note, recent outbreak strains in Guangdong Province, China (2016) and

Table 1 Demographic and clinical symptoms of patients infected with CVA21

\begin{tabular}{lllll}
\hline Patient ID & $\begin{array}{l}\text { Collection } \\
\text { date }\end{array}$ & \multicolumn{2}{l}{$\begin{array}{l}\text { Demographic } \\
\text { profile }\end{array}$} & Upper respiratory symptoms presented \\
\cline { 3 - 4 } & & Age & Sex & \\
\hline 12 MYKLU412 & 2 May 2012 & 52 & Female & Cough, sore throat, sneezing, nasal discharge \\
12 MYKLU434 & 4 May 2012 & 16 & Male & $\begin{array}{l}\text { Severe headache and sore throat, cough, hoarseness of voice, sneezing, nasal congestion with } \\
\text { discharge }\end{array}$ \\
14MYKLU3370 & $\begin{array}{l}\text { 13 January } \\
\text { 2014 }\end{array}$ & 26 & Female & $\begin{array}{l}\text { Severe headache and nasal congestion, cough, sore throat, hoarseness of voice, sneezing, nasal } \\
\text { discharge, myalgia }\end{array}$ \\
\hline
\end{tabular}




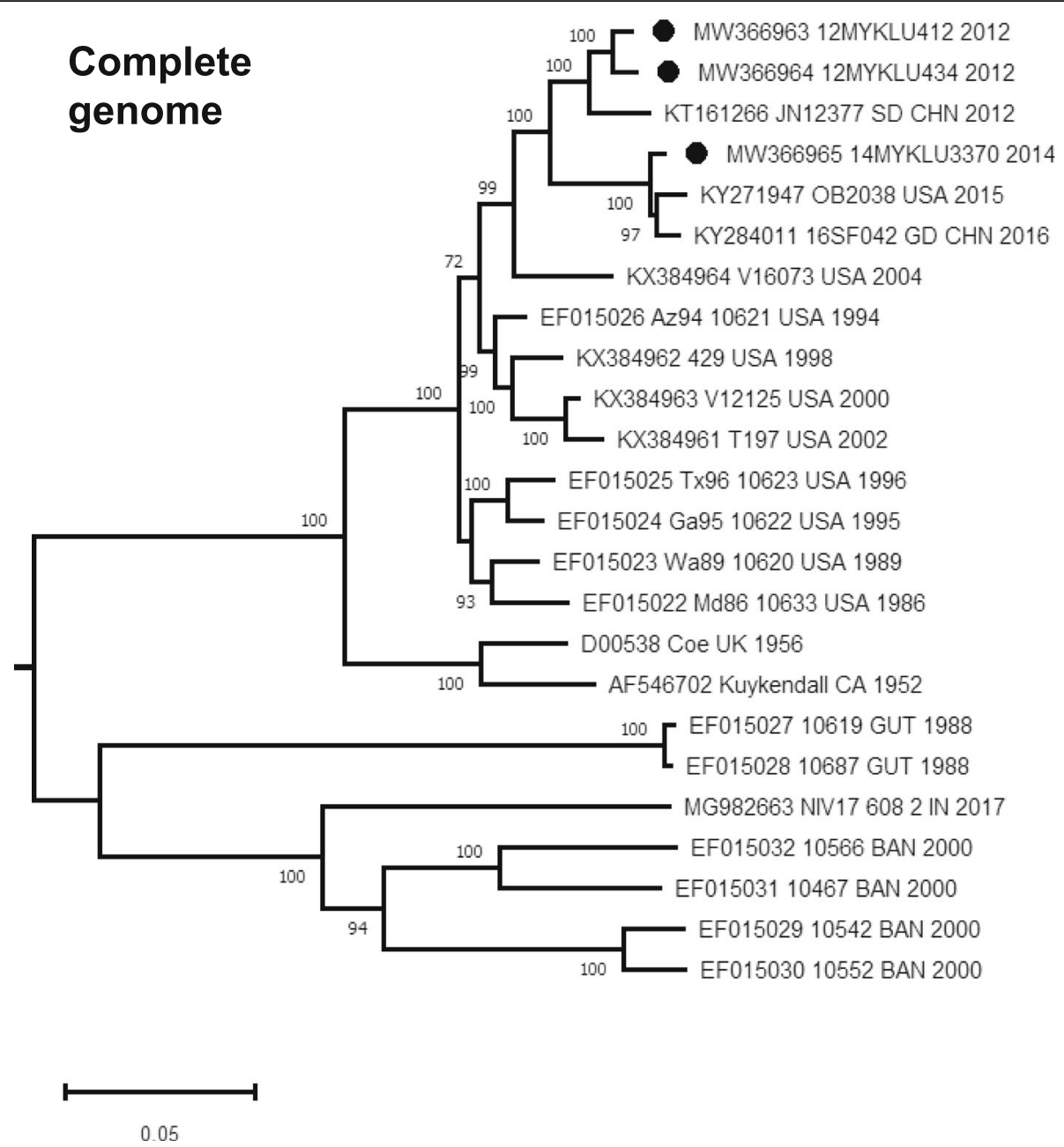

Fig. 1 Phylogenetic analysis of CVA21 complete genomes. Phylogenetic tree was reconstructed by the neighbour-joining method based on all available complete genomes of CVA21 $(n=24)$ using MEGA X. The reliability of the branching nodes was assessed by bootstrap analysis of 1000 replicates. Bootstrap values (> 70\%) are shown at the respective branches. Scale bar represents a genetic distance of 0.05 substitutions/site. Accession number, location and year of isolation are shown for previously published CVA21 genomes in GenBank. The newly generated sequences in this study are indicated in circle

Yamagata, Japan (2019) were characterized by profound founding effects with limited genetic diversity within the respective clusters. In addition, weak or limited spatial distribution is observed among CVA21 circulating worldwide with frequent strain mixing, suggesting active lineage mobility between regions. Interestingly, phylogenies within cluster I were characterized by a "ladder-like" structure resulting from the continual turnover of viral lineages through time. Cluster II meanwhile comprised of CVA21 strains originated from South Asia (India and Bangladesh), Central America (Guatemala) and Central Africa (Chad) (Fig. 2). Overall, the tree topology of the complete VP1 region observed was similar to that of the complete genomes in Fig. 1.
It is important to note that the surveillance and genomic data presented in the study contain several inherent limitations, such as the relatively old sampling period, limited sampling site and the inability to establish the seasonality of CVA21 due to the low detection rate. Therefore, the recent activity of CVA21 in the region remains unclear, highlighting the need for continuous sentinel surveillance involving multiple sites and timely reporting in order to facilitate effective outbreak response strategies.

\section{Conclusions}

In summary, we studied and characterised the distribution and complete genomes of CVA21 isolated from patients presenting with acute respiratory symptoms in 


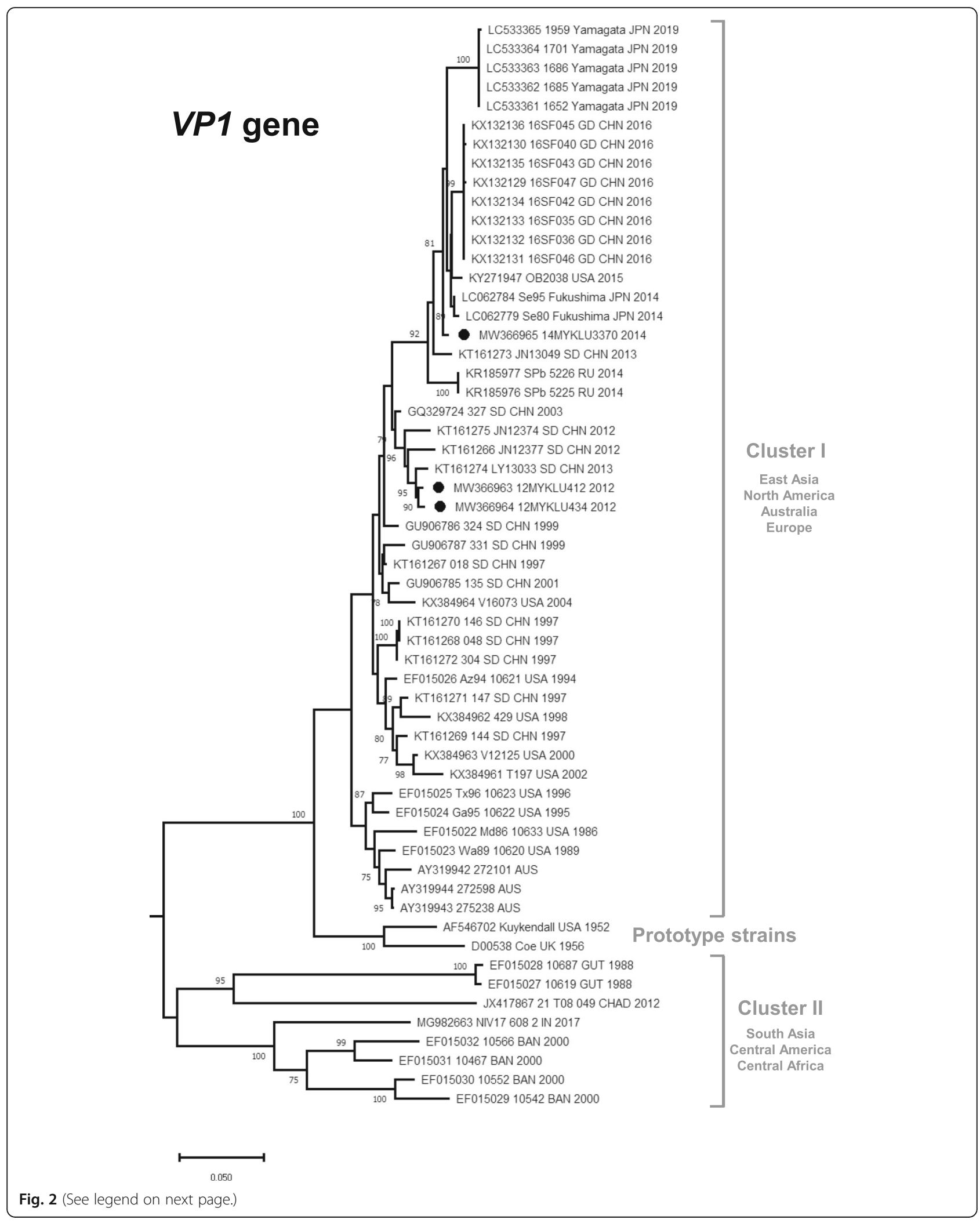


(See figure on previous page.)

Fig. 2 Phylogenetic analysis of the global CVA21 VP1 gene. Phylogenetic tree was reconstructed by the neighbour-joining method based on $n=54$ available complete CVA21 VP1 gene sequences (894 bp), equivalent to position 2497-3390 of the prototype strain (GenBank accession no. AF546702). CVA21 strains grouped within Cluster I (East Asia, North America, Australia and Europe) and Cluster II (South Asia, Central America and Central Africa) are indicated by brackets. The reliability of the branching nodes was assessed by bootstrap analysis of 1000 replicates. Bootstrap values (> 70\%) are shown at the respective branches. Scale bar represents a genetic distance of 0.05 substitutions/site. GenBank accession number, location and year of isolation are shown for previously reported CVA21 strains. The newly generated sequences in this study are indicated in circle

Malaysia, highlighting the emerging role of CVA21 in causing low-level but recurrent respiratory outbreaks. The evolutionary dynamics of global CVA21 strains showed widespread distribution of at least two major phylogenetic clusters worldwide.

\section{Abbreviations}

CVA21: Coxsackievirus A21; EV: Enteroviruses; nt: Nucleotides;

PCR: Polymerase chain reaction; UTR: Untranslated region

\section{Supplementary Information}

The online version contains supplementary material available at https://doi. org/10.1186/s12879-021-06148-x.

Additional file 1: Supplementary Table 1. Primer sequences used for complete genome amplification of Coxsackievirus A21.

\section{Acknowledgements}

The authors thank all study participants who contributed to the study.

\section{Authors' contributions}

Conceived and designed the experiments: NIS, KTN, KKT. Performed the experiments: NIS, KTN, JBC, KKT. Analyzed the data: NIS, KTN, JBC, YT, KGC, KKT. Contributed reagents/material: NIS, KTN, JBC, YT, KGC, KKT. Wrote and reviewed the manuscript: NIS, KTN, JBC, YT, KGC, KKT. The author(s) read and approved the final manuscript.

\section{Funding}

This work was supported in part by grants to K.K.T from the Ministry of Higher Education, Malaysia (High Impact Research UM.C/625/1/HIR/MOE/ CHAN/02/02 and Fundamental Research Grant Scheme FRGS/1/2020/SKKO/ UM/02/17) and Faculty Research Grant GPF002C-2019. The funding bodies did not play any role in the design of the study and collection, analysis, and interpretation of data and in writing the manuscript.

\section{Availability of data and materials}

The CVA21 genome sequences are available in GenBank under the following accession numbers: MW366963-MW366965. The sample collection dates and isolation source are available in the National Center for Biotechnology Information (NCBI) public database. Public access to the database is open.

\section{Declarations}

Ethics approval and consent to participate

This study was approved by the University Malaya Medical Ethics Committee (reference number 890.1). Written consent was obtained from all patients. Patients were briefed about the nature of the research in terms of methodology, possible adverse effects and complications. Patients were aware that they can withdraw from this research at any time without assigning any reason whatsoever and in such a situation shall not be denied the benefits of usual treatment by the attending doctors.

\section{Consent for publication}

Not applicable.

\section{Competing interests}

The authors declared no competing interests exist.

\section{Author details}

${ }^{1}$ Department of Medical Microbiology, Faculty of Medicine, University of Malaya, Kuala Lumpur, Malaysia. ${ }^{2}$ Department of Medicine, Faculty of Medicine, University of Malaya, Kuala Lumpur, Malaysia. ${ }^{3}$ Infectious Disease Translational Research Programme, Yong Loo Lin School of Medicine, National University of Singapore, Singapore, Singapore. ${ }^{4}$ Department of Microbiology and Immunology, Yong Loo Lin School of Medicine, National University Health System, National University of Singapore, Singapore, Singapore. ${ }^{5}$ Department of Medical Sciences, School of Healthcare and Medical Sciences, Sunway University, Bandar Sunway, Selangor Darul Ehsan, Malaysia. ${ }^{6}$ AIDS Research Center, National Institute of Infectious Diseases, Toyama, Shinjuku-ku, Tokyo, Japan. ${ }^{7}$ Division of Genetics and Molecular Biology, Institute of Biological Sciences, Faculty of Science, University of Malaya, Kuala Lumpur, Malaysia. ${ }^{8}$ International Genome Centre, Jiangsu University, Zhenjiang, China.

Received: 7 February 2021 Accepted: 6 May 2021

Published online: 17 May 2021

\section{References}

1. Simmonds $P$, Gorbalenya AE, Harvala H, Hovi T, Knowles NJ, Lindberg $\mathrm{AM}$, et al. Recommendations for the nomenclature of enteroviruses and rhinoviruses. Arch Virol. 2020;165(3):793-7. https://doi.org/10.1007/ s00705-019-04520-6.

2. Walker PJ, Siddell SG, Lefkowitz EJ, Mushegian AR, Adriaenssens EM, Dempsey DM, et al. Changes to virus taxonomy and the statutes ratified by the international committee on taxonomy of viruses (2020). Arch Virol. 2020;165(11):2737-48. https://doi.org/10.1007/ s00705-020-04752-x.

3. Dalldorf $\mathrm{G}$, Sickles GM. An unidentified, filtrable agent isolated from the feces of children with paralysis. Science (Washington). Science. 1948; 108(2794):61-2. https://doi.org/10.1126/science.108.2794.61.

4. Ikeda T, Aoki Y, Komabayashi K, Itagaki T, Mizuta K. Isolation of coxsackievirus A21 from patients with acute respiratory infection in Yamagata, Japan in 2019. Jpn J Infect Dis. 2020; (In press).

5. Xiang Z, Gonzalez R, Wang Z, Ren L, Xiao Y, Li J, et al. Coxsackievirus A21, enterovirus 68, and acute respiratory tract infection, China. Emerg Infect Dis. 2012;18(5):821-4. https://doi.org/10.3201/eid1805.111376.

6. Zou L, Yi L, Song Y, Zhang $X$, Liang L, Ni H, et al. A cluster of coxsackievirus A21 associated acute respiratory illness: the evidence of efficient transmission of CVA21. Arch Virol. 2017;162(4):1057-9. https://doi.org/10.1007/s00705-016-3201-4.

7. Hang J, Vento TJ, Norby EA, Jarman RG, Keiser PB, Kuschner RA, et al. Adenovirus type 4 respiratory infections with a concurrent outbreak of coxsackievirus A21 among United States Army Basic Trainees, a retrospective viral etiology study using next-generation sequencing. J Med Virol. 2017;89(8):1387-94. https://doi.org/10.1002/jmv.24792.

8. Linster M, Donato C, Mah MG, Grau ML, Low JG, Ooi EE, et al. Genetic diversity of respiratory enteroviruses and rhinoviruses in febrile adults, Singapore, 2007-2013. Influenza Other Respir Viruses. 2020;14(1):67-71. https://doi.org/10.1111/irv.12662.

9. Wang $S, X u$ M, Lin X, Liu Y, Xiong $P$, Wang L, et al. Molecular characterization of coxsackievirus A21 in Shandong, China. Arch Virol. 2016;161(2):437-44. https://doi.org/10.1007/s00705-015-2669-7.

10. Okomo U, Idoko OT, Kampmann B. The burden of viral respiratory infections in young children in low-resource settings. Lancet Glob Health. 2020;8(4): e454-5. https://doi.org/10.1016/S2214-109X(20)30037-1.

11. Ng KT, Oong XY, Lim SH, Chook JB, Takebe Y, Chan YF, et al. Viral load and sequence analysis reveal the symptom severity, diversity, 
and transmission clusters of rhinovirus infections. Clin Infect Dis. 2018, 67(2):261-8. https://doi.org/10.1093/cid/ciy063.

12. Kumar S, Stecher G, Li M, Knyaz C, Tamura K. MEGA X: molecular evolutionary genetics analysis across computing platforms. Mol Biol Evol. 2018;35(6):1547-9. https://doi.org/10.1093/molbev/msy096.

13. Khetsuriani N, Lamonte-Fowlkes A, Oberst S, Pallansch MA.

Enterovirus surveillance--United States, 1970-2005. MMWR Surveill Summ. 2006;55:1-20.

14. Hughes PJ, North C, Minor PD, Stanway G. The complete nucleotide sequence of coxsackievirus A21. J Gen Virol. 1989;70(Pt 11):2943-52. https:// doi.org/10.1099/0022-1317-70-11-2943.

\section{Publisher's Note}

Springer Nature remains neutral with regard to jurisdictional claims in published maps and institutional affiliations.

Ready to submit your research? Choose BMC and benefit from:

- fast, convenient online submission

- thorough peer review by experienced researchers in your field

- rapid publication on acceptance

- support for research data, including large and complex data types

- gold Open Access which fosters wider collaboration and increased citations

- maximum visibility for your research: over $100 \mathrm{M}$ website views per year

At BMC, research is always in progress.

Learn more biomedcentral.com/submissions 